\title{
Analisis Faktor Produksi Kelapa Sawit Rakyat Menurut Tipologi Lahan di Kabupaten Indragiri Hilir Provinsi Riau
}

\author{
Analysis of the Production Factors of the People's Palm Oil According to the Land \\ Typology in Indragiri Hilir Regency, Riau Province \\ Heriyanto Heriyanto $^{1 *}$, Asrol Asrol ${ }^{1}$, Detri Karya ${ }^{2}$, Verry Yarda Ningsih ${ }^{3}$ \\ ${ }^{1}$ Program Studi Agribisnis, Fakultas Pertanian, Universitas Islam Riau, Riau 28284 \\ ${ }^{2}$ Program Studi Manajemen, Fakultas Ekonomi Universitas Islam Riau, \\ Kota Pekanbaru, Riau 28284 \\ ${ }^{3}$ Program Studi Agribisnis, Fakultas Pertanian Universitas Musi Rawas, Kota \\ Lubuklinggau, Sumatera Selatan 31625 \\ ${ }^{*}$ Penulis untuk korespondensi: heriyanto@agr.uir.ac.id
}

\begin{abstract}
Palm oil commodities are one of the plantation sub-sector commodities that increase the income of farmers and the community, provide processing industry raw materials that create added value. The land cultivated by independent oil palm farmers consists of land land, tidal peatlands, coastal peatlands and coastal land. The difference in typology of this land will contribute to different production. The research aimed to analyze the oil palm production and the dominant factor affecting oil palm production according to the typology of land in Indragiri Hilir Riau Province. The data were analyzed using descriptive statistics and built multiple regression models with the dummy variable method of Ordinary Least Square (OLS). The results of the study showed that the production of oil palm cultivation on land is the highest compared to the typology of tidal peatland, coastal peat and coastal land. The dominant factors affecting palm oil production in Indragiri Hilir Regency were the amount of fertilizer use, labor, age of plants, herbicides and dummy typology of land. In order to obtain optimal production, this study recommended doing oil palm farming in accordance with the correct cultivation techniques in accordance with the characteristics of land typology. Besides that the use of balanced fertilizer (elements of $\mathrm{N}$, $\mathrm{P}$, and $\mathrm{K}$ ) in accordance with the recommended needed to be applied.
\end{abstract}

Keywords: dominant factors, land typology, oil palm, production

\begin{abstract}
ABSTRAK
Komoditas kelapa sawit merupakan salah komoditi sub sektor perkebunan yang dapat meningkatkan pendapatan petani dan masyarakat, penyedia bahan baku industri pengolahan yang menciptakan nilai tambah. Lahan yang diusahakan oleh petani kelapa sawit swadaya terdiri dari lahan daratan, lahan gambut pasang surut, lahan gambut pesisir dan lahan pesisir. Perbedaan tipologi lahan ini akan memberikan kontribusi terhadap produksi yang berbeda. Tujuan penelitian untuk menganalisis produksi kelapa sawit dan faktor dominan yang mempengaruhi produksi kalapa sawit rakyat menurut tipologi lahan di Kabupaten Indragiri Hilir Provinsi Riau. Untuk menjawab penelitian ini di analisis dengan deskriptif statistic dan membangun model regesi berganda dengan variable dummy metode Ordinary Least Square $(O L S)$. Hasil penelitian memperlihatan bahwa produksi usahatani kelapa sawit pada lahan daratan paling tinggi dibandingkan dengan tipologi
\end{abstract}


lahan gambut pasang surut, gambut pesisir dan lahan pesisir. Faktor yang dominan mempengaruhi produksi kelapa sawit di Kabupaten Indragiri Hilir adalah jumlah penggunaan pupuk, tenaga kerja, umur tanaman, herbisida dan dummy tipologi lahan daratan. Dalam rangka memperoleh produksi yang optimal, penelitian ini merekomendasikan melakukan usahatani kelapa sawit sesuai dengan teknis budidaya yang benar sesuai dengan karakterisitik tipologi lahan. Disamping itu penggunaan pupuk berimbang (unsur N, P, dan K) sesuai dengan yang diajurkan perlu diterapkan.

Kata kunci: faktor dominan, kelapa sawit, produksi, tipologi lahan

\section{PENDAHULUAN}

Komoditas kelapa sawit merupakan salah komoditi sub sektor perkebunan yang dapat meningkatkan pendapatan petani dan masyarakat, penyedia bahan baku industri pengolahan yang menciptakan nilai tambah. Selain itu, tanaman kelapa sawit juga menjadi sumber pangan dan gizi utama dalam menu penduduk, sehingga kelangkaannya di pasar domestik berpengaruh sangat nyata dalam perkembangan ekonomi dan kesejahteraan masyarakat.

Provinsi Riau sebagai salah satu Provinsi yang memiliki perkebunan kelapa sawit terluas di Indonesia, pada tahun 2017 luas perkebunan mencapai luas 2.776 .500 ha dengan produksi sebesar 9.071.400 ton yang tersebar di dua belas Kabupaten dan Kota (Badan Pusat Statistik, 2017). Perkebunan tersebut dikelola dalam 3 bentuk badan usaha yaitu: (1) perkebunan besar yang dikelola oleh Badan Usaha Milik Negara (BUMN) yaitu dikelola oleh PT. Perkebunan Nusantara V, (2) Perkebunan Besar Swasta Nasional (PBSN) yang dikelola oleh perusahaan swasta besar, dan (3) perkebunan rakyat yang dikelola oleh rumah tangga dalam bentuk usaha perorangan atau yang diusahakan secara swadaya.

Perkebunan kelapa sawit di Kabupaten Indragiri Hilir menepati urutan kelima di Provinsi Riau, berdasarkan data Satistik perkebunan luas kelapa sawit di Kabupaten Indragiri Hilir pada tahun 2013 seluas 109.017 ha dengan produksi sebesar 249.604 ton dan pada tahun 2017 meningkat menjadi seluas 117.820 ha dengan produksi sebesar 721.084 ton yang diusahakan oleh 79.545 kepala keluarga yang menyebar di seluruh wilayah Kabupaten Indragiri Hilir dan didukung oleh 12 pabrik kelapa sawit (PKS). Kecamatan yang memiliki kebun kelapa sawit rakyat terluas adalah Kecamatan Kemuning dengan luas 39,388 ha dengan produksi 117,243 ton yang dikelola oleh 34.363 kepala keluarga, sedangkan kecamatan yang memiliki luas kebun kelapa sawit rakyat terkecil adalah kecamatan Kuala Indragiri luas 39,00 ha dengan produksi 57,00 ton yang dikelola oleh 35 kepala keluarga (BPS 2016a, 2016b).

Produksi dan produktivitas perkebunan kelapa sawit rakyat pola swadaya masih tertinggal dibandingkan perkebunan besar negara, swasta dan plasma. Rendahnya produktivitas ini disebabkan tanaman sudah tua dan memerlukan peremajaan (replanting), kurangnya permodalan dan penguasaan teknologi, tidak ada perencanaan penggantian tanaman yang teratur sesuai umur tanaman dan sebagainya (Daim, 2003). Pendapatan petani plasma pada tipologi lahan kering lebih tinggi 29,95\% dibandingkan pada lahan basah yang disebabkan karena produksivitas pada lahan kering sebesar rata-rata 20.310 $\mathrm{kg} / \mathrm{ha} / \mathrm{thn}$ dan pada lahan basah sebesar rata-rata $18.809,52 \mathrm{~kg} / \mathrm{ha} / \mathrm{thn}$ (Lifianthi et al. 2014).

Komoditi kelapa sawit berbeda dengan komoditi perkebunan lain, karena memerlukan pabrik yang dekat dengan petani, agar buah yang dihasilkan dapat segera dikirim ke pabrik (dalam waktu \pm 24 jam) supaya kualitas minyak tidak mengandung asam lemak yang tinggi (Gatto et al. 2017; Harahap et al. 2017). 
Keberadaan pabrik kelapa sawit di Kabupaten Indragiri Hilir belum sepenuhnya mampu di jangkau oleh petani, mayoritas pabrik berada pada tipologi lahan daratan sehingga petani tipologi lahan basah (gambut pasang surut, gambut pesisir dan pesisir) yang masih mengandalkan sarana transportasi air dan darat membutuhkan waktu lebih lama dan biaya lebih besar.

Pengembangan agribisnis kelapa sawit di Kabupaten Indragiri Hilir mengarah pada wilayah dataran rendah atau lahan basah. Daerah yang memiliki dataran lahan kering tidak bisa dilakukan pengembangan karena sebagian merupakan kawasan lindung yaitu Taman Nasional Bukit Tiga Puluh dan dataran tinggi lainya sudah diusahakan menjadi perkebunan kelapa sawit, kelapa sawit, pemukiman dan penggunaan lahan lainya sehingga untuk perluasan kelapa sawit dilakukan dengan cara alih fungsi lahan. Perluasan kelapa sawit swadaya pada lahan basah dilakukan pada daerah rawa dan pesisir pantai, yaitu daerah aliran sungai yang menjorok ke dalam masih pengaruh gerakan pasang. Berdasarkan luapan dan salinitas lahan rawa di Kabupaten Indragiri Hilir dapat dibedakan menjadi tiga tipologi yaitu gambut air tawar, gambut air payau. dan pesisir (Noor 2004). Dengan demikian tipologi lahan menyebabkan terjadinya perbedaan pendapatan petani akibat mahalnya harga input dan murahnya harga output.

Masalah yang dihadapi petani kelapa sawit swadaya di Kabupaten Indragiri Hilir adalah masalah teknis dan masalah sosial-ekonomis. Secara teknis pembangunan kebun kelapa sawit di daerah lahan basah terutama lahan lahan rawa adalah termasuk lahan marginal, yaitu lahan yang identik dengan sulfat masam, memiliki sifat fisika, kimia dan biologi yang lebih buruk dibandingkan dengan tanah daratan. Kendala pengembangan pada lahan rawa antara lain kondisi lahan yang tidak seragam dan lokasi yang terpencar, sehingga menyulitkan pengendalian hama dan penyakit serta pengendalian pola tata air. Lahan rawa memiliki produktivitas lebih rendah dan sangat rendah dibandingkan tanah daratan (Noor 2004).

Faktor produksi dalam usahatani kelapa sawit terdiri dari alam atau lahan, sarana produksi, dan tenaga kerja. Lahan yang diusahakan oleh petani kelapa sawit swadaya terdiri dari lahan daratan, lahan gambut pasang surut, lahan gambut pesisir dan lahan pesisir. Tipologi lahan ini akan memberikan kontribusi terhadap produksi yang berbeda. Tujuan penelitian untuk menganalisis produksi kelapa sawit dan faktor dominan yang mempengaruhi produksi kalapa sawit rakyat menurut tipologi lahan di Kabupaten Indragiri Hilir Provinsi Riau.

\section{BAHAN DAN METODE}

Penelitian ini dilakukan di Kabupaten Indragiri Hilir Provinsi Riau karena memiliki tipolgi jenis lahan daratan, gambut pasang surut, gambut pesisir dan lahan pesisir. Penelitian menggunakan metode pengambilan sampel Multistage Area Sampling dengan mengacu pada peta RTRW digunakan untuk memilih wilayah kecamatan yang representatif (petani swadaya) di Kabupaten Indragiri Hilir dapat dilihat pada Tabel 1.

Sampel yang diambil adalah Kecamatan Kemuning, Keritang, Kempas, Gaung dan Tempuling mewakili kecamatan kategori tinggi. Kecamatan Reteh, Batang Tuaka dan Gaung Anak Serka mewakili kecamatan kategori sedang dan Kecamatan Enok. Kateman, Pulau Burung, dan Concong mewakili kecamatan dengan areal kelapa sawit kategori rendah. Menurut tipologi desa dan observasi lapangan ditetapkan 20 desa sampel pada 11 area kecamatan dengan total sampel sebanyak 92 responden.

\section{Analisis Data}

Untuk menganalisis Produksi kelapa sawit menurut tipologi lahan menggunakan 
analisis statistik deskriptif. Selanjutnya untuk menganalisis faktor dominan yang mempengaruhi produksi kelapa sawit rakyat di Kabupaten Indragiri Hilir berdasarkan tipologi lahan menggunakan model regesi berganda dengan variable dummy metode Ordinary Least Square (OLS). Secara matematik fungsi model regresi adalah sebagai berikut:

$Y=b_{0}+b_{1} X_{1}+b_{2} X_{2}+b_{3} X_{3}+b_{4} X_{4}+b_{5} X_{5}+b_{6} D_{1}+b_{7} D_{2}+b_{8} D_{3}+b_{9} D_{4}+u$

Dimana:

$\mathrm{Y}=$ Produksi Kelapa Sawit (Kg/tahun)

$\mathrm{X} 1=$ Jumlah Pokok(batang)/ha

$\mathrm{X} 2=$ Jumlah Pupuk $(\mathrm{kg} / \mathrm{ha})$

$\mathrm{X} 3=$ Tenaga Kerja (HOK/ha/tahun)

$\mathrm{X} 4=$ Umur Tanaman (Tahun)

X5 $=$ Herbisida (Ltr/ha)

D1= Jenis Lahan

D1= 0 Lahan Peisir

D1=1 Selain Lahan Peisir

D2= Jenis Lahan

D2= 0 Lahan Gambut Pasang Surut

Sebelum dilakukan estimasi model regresi berganda, data yang digunakan harus dipastikan terbebas dari penyimpangan asumsi klasik untuk multikolinearitas, heteroskesdasitas, dan autokorelasi (Gujarati 2008; 2011, Intriligator 1978; Pindyck \& Rubinfeld 1998; Thomas 1977; Verbeek 2000). Uji klasik ini dapat dikatakan sebagai kriteria ekonometrika untuk melihat apakah hasil estimasi memenuhi dasar linear klasik atau tidak. Dengan terpenuhinya asumsi-asumsi klasik ini maka estimator Ordinary Least Square (OLS) dari koefisien regresi adalah penaksir tak bias linear terbaik BLUE (Best Linear Unbiased Estimator) (Gujarati, 2003, 2008, 2011; Pindyck \& Rubinfeld, 1998; Thomas, 1977; Verbeek, 2000), agar tahap estimasi yang diperoleh benar dan efektif. Salah satu asumsi yang harus dipenuhi untuk memenuhi sifat BLUE adalah homoskedastisitas, bila asumsi tersebut tidak terpenuhi maka yang terjadi adalah sebaliknya, yakni heteroskedastisitas yang artinya variansi error tidak konstan. Variansi error yang tidak konstan ini menyebabkan kesimpulan yang dicapai tidak valid atau bias.

Agar memberikan hasil yang valid secara ekonometrik perlu dilakukan
D2 = 1Lahan Selain Gambut Pasang Surut

D3= Jenis Lahan

D3= 0 Lahan Daratan

D3= 1 Selain Lahan Daratan

D4= Jenis Bibit :

D4= 0 Jenis Bibit Unggul

D4= 1 Selain Jenis Bibit Unggul

$\mathrm{b} 0=$ Intersep

$\mathrm{b}_{1} \ldots \mathrm{b}_{7}$

$\mathrm{u}=$ Kesalahan pengganggu

pengujian beberapa asumsi ekonometrika yang meliputi pendekteksian normalitas, multikolinieritas, heteroskedastisitas dan autokorelasi dari persamaan dalam model regresi (Gujarati 2003; 2008; 2011; Pindyck dan Rubinfeld 1998; Thomas 1977; Verbeek 2000).

Pendeteksian normalitas dilakukan untuk mengetahui apakah variabel berdistribusi normal atu tidak dengan menggunakan Shapiro-Wilk dengan formula sebagai berikut (Intriligator, 1978; Pindyck \& Rubinfeld, 1998; Thomas, 1977; Verbeek, 2000, 2017):

$$
\begin{aligned}
& \mathrm{W}=\frac{\left[\sum_{i}^{h} a_{n}\left(\tilde{\mathrm{e}}_{(V-1+1)}-\tilde{\mathrm{e}}_{(i)}\right)\right]^{2}}{\sum_{i=1}^{h}\left(\tilde{\mathrm{e}}_{i}-\tilde{\mathrm{e}}\right)^{2}} \\
& \mathrm{~V}=\mathrm{T}-\mathrm{knj}
\end{aligned}
$$

$\mathrm{H}=\mathrm{n} / 2$ untuk bilangan genap atau (n-1) untuk bilangan ganjil, dimana $: \mathrm{v}=$ derajat bebas; $\mathrm{T}=$ jumlah observasi; $\mathrm{K}=$ jumlah variabel; ain $=$ parameter dari statistik Shapiro-Wilk.

Uji multikolinieritas digunakan untuk mengetahui apakah terdapat korelasi antara peubah independen dalam model regresi. Untuk mendektesi multikolinieritas dalam suatu model dilakukan dengan melihat Variance Inflation Factor (VIF) 
dengan persamaan, sebagai berikut Variance Inflation Factor $=1 /$ tolerance (Gujarati 2003, 2008; Thomas 1977):

Tabel 1. Jumlah Sampel Petani Kelapa Sawit Swadaya Menurut Tipologi Lahan dan Desa di Kabupaten Indragiri Hilir

\begin{tabular}{|c|c|c|c|c|}
\hline No. & Tipologi Lahan & Kecamatan & Desa & Sampel \\
\hline \multirow{7}{*}{1} & Wilayah Daratan & Kemuning & Sekara & 10 \\
\hline & & & Kemuning Muda & 11 \\
\hline & & & Limau Manis & 9 \\
\hline & & & Tuk Jimun & 2 \\
\hline & & Keritang & Pancur & 2 \\
\hline & & & Jumlah & 34 \\
\hline & Wilayah Gambut Pasang & & & \\
\hline \multirow[t]{11}{*}{2} & Surut & Kemuning & Limau Manis & 1 \\
\hline & & & Lubuk Besar & 3 \\
\hline & & Keritang & Sencalang & 6 \\
\hline & & & Pancur & 1 \\
\hline & & Kempas & Rumbai Jaya & 3 \\
\hline & & & Harapan Jaya & 4 \\
\hline & & & Harapan Tani & 4 \\
\hline & & & Pekan Tua & 4 \\
\hline & & Tempuling & Tempuling & 2 \\
\hline & & & Karya Tunas Jaya & 4 \\
\hline & & & Jumlah & 32 \\
\hline \multirow[t]{9}{*}{3} & Wilayah Gambut Pesisir & Enok & Syuhada & 2 \\
\hline & & Tempuling & Sungai Salak & 2 \\
\hline & & Batang Tuaka & Tanjung Siantar & 2 \\
\hline & & Reteh & Sungai Undan & 2 \\
\hline & & & Sungai Terab & 2 \\
\hline & & & Sanglar & 3 \\
\hline & & Gaung Anak Serka & Rambaian & 2 \\
\hline & & & Sungai Empat & 2 \\
\hline & & & Jumlah & 17 \\
\hline \multirow[t]{5}{*}{4} & Wilayah Pesisir & Pulau Burung & Pulau Burung & 3 \\
\hline & & Pelangiran & Tanjung Simpang Kateman & 4 \\
\hline & & Concong & Kampung Baru & 2 \\
\hline & & & Jumlah & 9 \\
\hline & & Total Sampel & & 92 \\
\hline
\end{tabular}

Masalah multicollinearity menjadi sangat serius jika nilai variance inflation factor lebih besar dari 10 sedangkan masalah multicollinearity diangap tidak serius jika nilai variance inflation factor lebih kecil sama dengan 10.

Pendeteksian heteroskedastisitas

$$
\sigma_{i}^{2}=\sigma^{2} h\left(z_{i}^{1} \alpha\right)
$$

\section{Keterangan:}

$\mathrm{h}=$ unsur yang tidak diketahui, yaitu fungsi yang diturunkan secara kontinu (tidak tergantung pada i) digunakan untuk mengetahui apakah varian dari variabel pengganggu tidak konstan untuk semua observasi. Pendeteksian masalah heteroskedastisitas menggunakan Breusch-Pagan test (Pindyck dan Rubinfeld 1998; Thomas 1977; Verbeek sehingga $h()>$.0 dan $h(0)=1$. $\mathrm{s}=$ varian

$\mathrm{z} \quad=$ peubah yang mempengaruhi distrubance terms variance. 2017) di bawah ini: 
Nilai Statistik Bruesch-Pagan yang tidak signifikan menunjukkan tidak terjadi masalah heteroskedastisitas.

Autokolerasi digunakan untuk mengetahui apakah dalam suatu model regresi linier terdapat korelasi antara anggota observai satu dnegan observasi lain yang berlainan waktu. Untuk menguji autokorelasi dengan menggunakan Durbin Watson, dengan formula sebagai berikut (Pindyck dan Rubinfeld 1998; Thomas 1977; Verbeek 2017):

$\mathrm{d}=\frac{\left[\sum_{t=1}^{t=n}\left(\hat{\mathrm{e}}_{t}-\hat{\mathrm{e}}_{t-1}\right)\right]}{\sum_{t=1}^{t=n} \hat{\mathrm{e}}_{t}^{2}}$

Keterangan: $d=$ koefisien Durbin-Watson; $\mathrm{t}$ $=\mathrm{t}$ hitung; $\mathrm{n}=$ sampel; $\mathrm{e}=$ residual. Nilai $\mathrm{d}$ yang diperoleh dibandingkan dengan nilai du dan dL, jika $0<\mathrm{d}<\mathrm{dL}$ atau $4-\mathrm{dL}<\mathrm{d}<$ 4 berarti terdapat autokorelasi, bila nilai $\mathrm{d}$ terletak antara $\mathrm{dL}<\mathrm{d}<\mathrm{du}$ atau $4-\mathrm{du}<\mathrm{d}<$ $\mathrm{d}<\mathrm{dL}$ berarti tidak dapat dipastikan adanya autokorelasi, bilamana $\mathrm{du}<\mathrm{d}<4-\mathrm{du}$ berarti tidak ada autokorelasi positif/negatif.

\section{PEMBAHASAN}

\section{Produksi TBS Kelapa Sawit berdasarkan Tipologi Lahan}

Produksi kelapa sawit adalah hasil yang diperoleh petani kelapa sawit dari hasil proses penggolahan atau pengelolaan usahatani kelapa sawit. Produksi merupakan salah satu faktor penentu besarnya penerimaan yang diperoleh petani selain harga. Semakin tinggi produksi kelapa sawit semakin tinggi penerimaan yang diperoleh petani, jika harga tetap. Dengan demikian petani kelapa sawit berusaha memperoleh produksi yang maksimal.

Produksi kelapa sawit rakyat (pola swadaya) yang dihasilkan setiap tipologi lahan berbeda di Kabupaten Indragiri Hilir. Untuk mengetahui produksi kelapa sawit rakyat berdasarkan tipologi lahan dapat dilihat pada Gambar 1. Dari tabel tersebut menunjukkan bahwa rata-rata produksi kelapa sawit pola swadaya yang dihasilkan paling tinggi hingga terendah secara berturut-turut pada lahan daratan sebesar $11.351,7 \mathrm{~kg} / \mathrm{ha} / \mathrm{thn}$ berikutnya pada lahan gambut pasang surut sebesar $9.703,2 \mathrm{~kg} / \mathrm{ha} / \mathrm{thn}$, disususl produksi pada lahan gambut pesisir sebesar 9.344,9 $\mathrm{kg} / \mathrm{ha} / \mathrm{thn}$ dan pada tipologi lahan pesisir sebesar pesisir 7.250,5 kg/ha/thn.

Perbandingan produksi dapat dilihat pada Gambar 1. Berdasarkan Gambar 1 menunjukan bahwa tingginya produksi padaTBS pada tipologi lahan daratan dipengaruhi oleh jenis lahan, jenis bibit, penggunaan pupuk, pemeliharaan dengan cara penyemprotan herbisida dan dengan cara penebasan. Petani pada tipologi lahan daratan seluruhnya menggunakan jenis bibit unggul jenis Topaz, Marihat dan Lonsum. Sedangkan pada tipologi lahan lainya ada yang menggunakan jenis bibit tidak jelas. Pada tipologi lahan daratan petani mayoritas menerapkan pola tanam segitiga sama sisi sedangkan pada tipologi lahan lainya petani mayoritas menerapkan pola tanam segi empat dan tidak beraturan.

Pada saat penanaman bibit kelapa sawit petani pada tipologi lahan daratan sebanyak 52,94\% menggunakan pupuk, sedangkan pada tipologi lahan gambut pasang surut sebanyak 43,75\%, gambut pesisir sebanyak $29,41 \%$ dan pada lahan pesisir sebanyak 33,33\%.pada masa TM petani yang melakukan pemupukan pada tipologi lahan daratan sebanyak $88,24 \%$, pada tipolgo lahan gambut pasang surut sebanyak $18,75 \%$, pada tipologi lahan gambut pesisir sebanyak $76,47 \%$ dan pada tipologi lahan pesisir seluruhnya atau $100 \%$ menggunakan pupuk.

\section{Faktor Dominan Yang Mempengaruhi Produksi Kelapa Sawit}

Hasil pendugaan model faktor produksi kelapa sawit dalam penelitian ini sangat baik sebagai mana terlihat dari koefisien determinasi $\left(\mathrm{R}^{2}\right)$ yaitu 0,6809 . Hal ini menunjukkan bahwa 68,09 persen peubah jumlah produksi dapat dijelaskan 
oleh peubah jumlah pokok, jumlah pupuk, penggunaan tenaga kerja, umur tanaman, herbisida, Dummy lahan pesisir, dummy lahan gambut pasang surut, dummy lahan daratan dan dummy jenis bibit. Sedangkan
31,01 persen dipengaruhi oleh peubah lain yang tidak termasuk dalam model. Variasi ini signifikan pada taraf nyata 1 persen yang dilihat dari F hitung sebesar 19,2 dan probabilitas $<0,0001$.

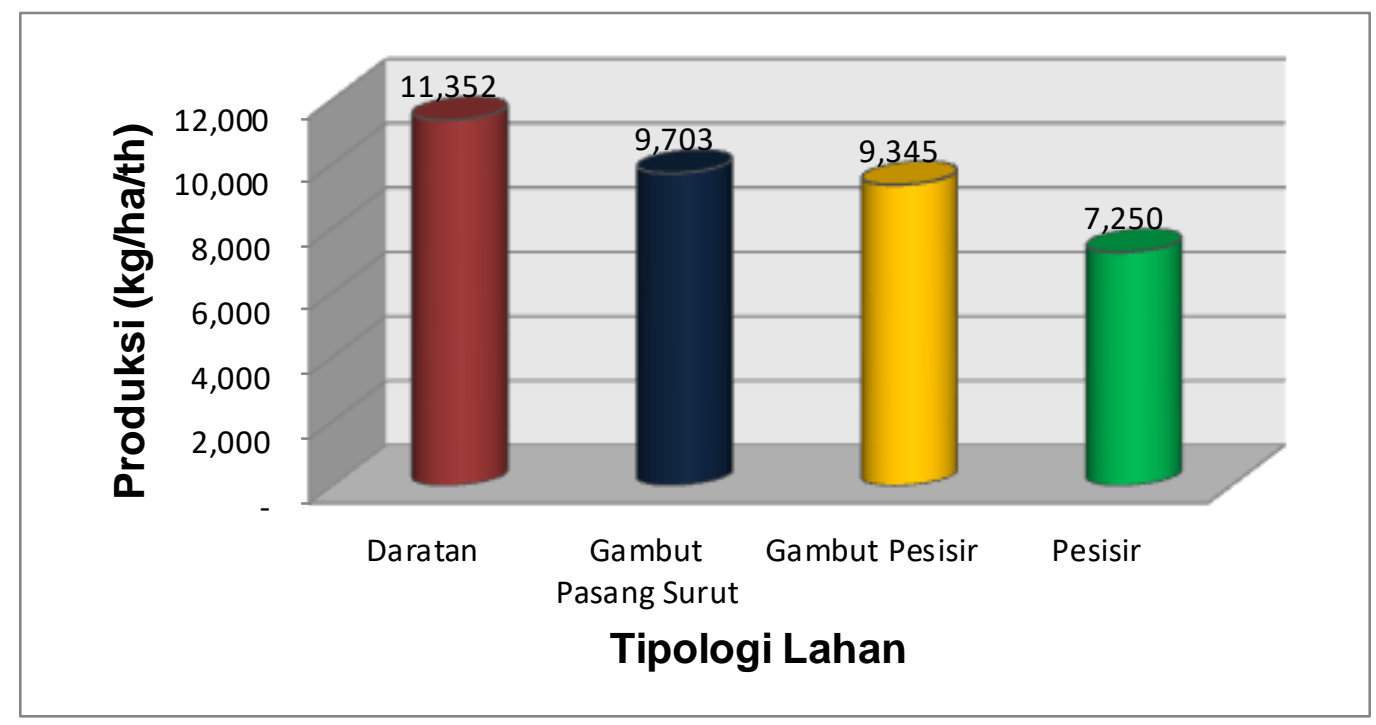

Gambar 1. Produksi rata-rata TBS berdasarkan tipologi lahan.

Hasil uji normalitas dengan menggunakan statistik Shapiro-Wilk memperlihatkan bahwa hasil perhitungan statistik Shapiro-Wilk untuk produksi kelapa sawit sebesar 0,05. Nilai tersebut signifikan pada taraf nyata 10 persen. Uji multikolinieritas nilai VIF untuk semua peubah independen (jumlah pokok, jumlah pupuk, penggunaan tenaga kerja, umur tanaman, herbisida, Dummy lahan pesisir, dummy lahan gambut pasang surut, dummy lahan daratan dan dummy jenis bibit) mempunyai nilai kurang dari 10. Hasil pengujian heteroskedasitas menunjukkan statistik Breusch-pagan sebesar 30,95 nilai tersebut berbedanyata dengan nol pada taraf nyata 10 persen. Nilai Durbin-Watson (DW) pada model yang dibangun yaitu sebesar 1,808 pada $\mathrm{n}=92$ dan $\mathrm{k}=8$ dari Tabel distribusi DW dengan taraf nyata 1 persen di peroleh nilai dL sebesar 1,336 dan du sebesar 1,714. Hal ini mengindikasikan bahwa data berditribusi normal, tidak terjadi multikoliniearitar, tidak terjadi heterokedasitas dan tidak terjadi autokorelasi.
Nilai koefisien regresi pada model fungsi produksi merupakan masing-masing peubah independen (jumlah pokok tanaman, jumlah pupuk, jumlah tenaga kerja, umur tanaman, herbisida, dummy lahan pesisir, dummy lahan gambut pesisir, dummy lahan daratan, dan dummy jenis bibit) seperti yang disajikan pada Tabel 2 . Berdasarkan tabel tersebut dapat dibuat persamaan regresi linear berganda sebagai berikut:

$\mathrm{Y}=-3.695,122+31,34824 \mathrm{X}_{1}+5,9176 \mathrm{X}_{2}$ $+28,35857 X_{3}+800,2312 X_{4}+138,0101$ $\mathrm{X}_{5}-1.931,714 \mathrm{D}_{1}-572,7889 \mathrm{D}_{2}+2.033,881$ $\mathrm{D}_{3}-1.554,361 \mathrm{D}_{4}$.

Faktor dominan yang mempengaruhi produksi kelapa sawit rakyat di kabupaten Indragiri Hilir dapat dilihat dari hasil pendugaan model faktor dominan yang mempegaruhi produksi usahatani kelapa sawit dapat dilihat pada Tabel 2. 
Tabel 2. Hasil pendugaan model faktor dominan yang mempengaruhi produksi kelapa sawit rakyat di Kabupaten Indragiri Hilir Provinsi Riau

\begin{tabular}{|c|c|c|c|c|c|}
\hline Variable & $\begin{array}{r}\text { Parameter } \\
\text { Estimate }\end{array}$ & $\begin{array}{r}\text { Standard } \\
\text { Error }\end{array}$ & t Value & $\operatorname{Pr}>|t|$ & $\begin{array}{l}\text { Variance } \\
\text { Inflation }\end{array}$ \\
\hline Intercept & $-3.695,122$ & $4.369,681$ & $-0,85$ & 0,4003 & 0 \\
\hline Jumlah Pokok (X1) & 31,34824 & 32,61984 & 0,96 & 0,3394 & 1,12891 \\
\hline Jumlah Pupuk (X2) & 5,9176 & 2,6101 & 2,27 & $0,026^{*}$ & 1,15698 \\
\hline Tenaga Kerja (X3) & 28,35857 & 7,35175 & 3,86 & $0,0002 *$ & 1,16492 \\
\hline Umur Tanaman (X4) & 800,2312 & 138,6076 & 5,77 & $<.0001 *$ & 2,08768 \\
\hline Herbisida (X5) & 138,0101 & 82,9744 & 1,66 & $0,1001^{*}$ & 1,05036 \\
\hline Lahan Gambut Pasang Surut (D1) & $-1.931,714$ & $1.326,81$ & $-1,46$ & 0,1493 & 1,17724 \\
\hline Lahan Pesisir (D2) & $-572,7889$ & 889,2131 & $-0,64$ & 0,5213 & 1,33265 \\
\hline Lahan Daratan (D3) & $2.033,881$ & $1.060,899$ & 1,92 & $0,0587^{*}$ & 1,952 \\
\hline Jenis Bibit (D4) & $-1.554,361$ & $1.159,238$ & $-1,34$ & 0,1837 & 1,15437 \\
\hline
\end{tabular}

Keterangan: * Signifikan pada taraf nyata 10 persen

Berdasarkan hasil pendugaan model pada Tabel 2 diketahui bahwa terdapat lima peubah yang berpengaruh nyata terhadap produsi kelapa sawit rakyat, yaitu jumlah pupuk, tenaga kerja, umur tanaman, herbisida dan dummy lahan daratan. Sedangkan jumlah pokok tanaman, dummy lahan gambut pasang surut, dummy lahan pesisir dan dummy jenis bibit tidak berpengaruh nyata terhadap produksi kelapa sawit rakyat di Kabupaten Indragiri Hilir. Selanjutnya Tabel 2 diatas menunjukkan bahwa peubah jumlah pokok tanaman, dummy lahan gambut pasang surut, dummy lahan pesisir dan dummy jenis bibit tidak signifikan atau tidak berpengaruh nyata terhadap peubah produksi kelapa sawit. Tidak berpengaruhnya faktor jumlah pokok tanaman karena petani kelapa sawit pola swadaya (rakyat) di Kabupaten Indragiri Hilir menerapkan pola tanam dan jumlah pokok tanaman yang bervariasi antara 70 300 pokok/hektar, sedangkan jumlah pokok tanaman yang ideal antara 128-143 pokok/hektar. Artinya penambahan jumlah pokok tanaman kelapa sawit tidak akan berpengaruh nyata terhadap produksi.

Lahan pesisir juga tidak berpengaruh nyata terhadap produksi dibandingkan dengan lahan lainya, hal ini disebabkan bahwa karakteristik lahan pesisir tidak berbeda nyata dengan lahan lainya (gambut pasang surut dan daratan).
Berikutnya lahan gambut pasang surut tidak pengaruh nyata terhadap produksi dibandingkan dengan lahan lainya (pesisir dan daratan), hal ini disebabkan bahwa seperti dijelaskan sebelumnya bahwa memiliki karakterisitik yang hampir sama lahan tersebut berada antara lahan pesisir dan daratan. Hal ini juga disebabkan pembuatan tanggul, saluran air, pintu air dan jalan produksi sebahagian besar belum tersedia dengan baik, selanjutnya transportasi produksi kelapa sawit rakyat di kabupaten Indragiri hilir sebahagian besar melalui taransportasi air.

Sedangkan jenis bibit tidak berpengaruh nyata terhadap produksi kelapa sawit di Kabupaten Indragiri Hilir disebabkan sulit dibedakan antara bibit unggul dan tidak unggul. Bibit unggul menurut petani tidak memiliki legalitas, karena petani membeli bibit unggul tersebut bukan langsung dari tempat penangkaran bibit tetapi dari pedagang pengecer dalam bentuk kecambah dan bibit jadi. Ditinjau dari aspek harga yang berlaku masih jauh dibawah harga bibit unggul yang sersertifikat. Sedangkan faktor produksi yang mempunyai pengaruh nyata terhadap produksi yaitu penggunaan jumlah pupuk, tenaga kerja, umur tanaman, pestisida dan dummy lahan daratan. Kelima faktor tersebut diuraikan sebagai berikut: 
1. Jumlah pupuk

Hasil estimasi yang di peroleh menunjukkan bahwa data penggunaan pupuk berpengaruh positif terhadap jumlah produksi kelapa sawit dan berbeda nyata dengan nol pada taraf nyata 10 persen sehingga hipotesis $\mathrm{H}_{0}$ ditolak dan hopotesis $\mathrm{H}_{\mathrm{a}}$ diterima. Artinya apabila jumlah pupuk ditambah sebesar satu kilogram maka akan meningkatkan produksi sebsesar 5,9176 kilogram. Hal ini disebakan pupuk merupakan sarana produksi yang mempunyai peranan penting dalam pertumbuhan kelapa sawit, kajian ini senada dengan (Mustofa et al. 2016).

Pertumbuhan kepala sawit yang baik akan memberikan produksi kelapa sawit. Selain itu, pupuk merupakan nutrisi bagi tanaman yang tidak seluruhhnya disediakan oleh alam atau yang tersedia oleh alam tidak mencukupi kebutuhan tanaman untuk diserap guna pertumbuhan dan proses produksi kelapa sawit. Mengingat bahwa usahatani kelapa sawit rakyat di Kabupaten Indragiri Hilir mayoritas berada pada lahan marginal.

\section{Tenaga Kerja}

Hasil estimasi yang di dapat menunjukkan bahwa data jumlah tenaga kerja berpengaruh positif terhadap jumlah produksi kelapa sawit di Kabupaten Indragiri Hilir dan berbeda nyata dengan nol pada taraf nyata 1 persen sehingga hipotesis $\mathrm{H}_{0}$ ditolak dan hipotesis $\mathrm{H}_{\mathrm{a}}$ diterima. Artinya apabila jumlah tenaga kerja meningkat sebesar satu HOK maka jumlah produksi juga akan meningkat sebsesar 28,35857 kilogram. Hal ini senada dengan kajian Heriyanto dan Darus, (2017) tenaga kerja berpengaruh nyata terhadap produksi tanaman perkebunan.

\section{Lahan Daratan}

Dari hasil estimasi yang diperoleh bahwa dummy lahan daratan berbengaruh positif terhadap dengan produksi kelapa sawit rskyat di Kabupaten Indragiri Hilir dan berbeda nyata dengan nol pada taraf nyata 1 persen sehingga hipotesis $\mathrm{H}_{0}$ ditolak dan hopotesis $\mathrm{H}_{\mathrm{a}}$ diterima. Artinya apabila petani melakukan usahatani kelapa sawit pada lahan daratan produksinya lebih tinggi dibandingkan dengan lahan lainnya (lahan gambut pasang surut dan lahan pesisir) sebesar 2.033,881 kg. Hal ini disebabkan bahwa lahan daratan merupakan lahan yang paling sesuai untuk berusahani kelapa sawit karena dapat mempengaruhi produksi sebesar 14.56\% (Dja'far et al. 2001).

\section{Umur Tanaman}

Hasil estimasi yang di dapat menunjukkan bahwa data umur tanaman berpengaruh positif terhadap jumlah produksi kelapa sawit dan berbeda nyata dengan nol pada taraf nyata 10 persen sehingga hipotesis $\mathrm{H} 0$ diterima dan hopotesis Ha ditolak. Artinya apabila umur tanaman meningkat maka jumlah produksi akan bertambah. Koefisien umur tanaman memiliki tanda positif yaitu sebesar 800,2312 yang berarti bahwa setiap peningkatan 1 tahun umur tanaman akan meningkatkan jumlah produksi sebesar $800,2312 \mathrm{~kg} / \mathrm{ha}$. Dengan demikian dapat disimpulkan bahwa apabila terjadi umur kelapa sawit rakyat di Kabupaten Indragiri Hilir sebahagian besar masih dalam usia produktif.

\section{Herbisida}

Hasil estimasi yang di dapat menunjukkan bahwa herbisida berpengaruh positif terhadap jumlah produksi kelapa sawit dan berbeda nyata dengan nol pada taraf nyata 10 persen sehingga hipotesis $\mathrm{H}_{0}$ diterima dan hipotesis Ha ditolak. Artinya apabila herbisida meningkat satu liter/ha maka jumlah produksi akan bertambah. Koefisien herbisida memiliki tanda positif yaitu sebesar 138,0101 yang berarti bahwa setiap peningkatan 1 liter/ha herbisida akan meningkatkan jumlah produksi kelapa sawit sebesar 138,0101 kg/ha. Dengan demikian dapat disimpulkan bahwa sebahagian besar kelapa sawit rakyat di Kabupaten Indragiri Hilir masih terdapat gulma pengganggu tanaman kelapa sawit sehingga ini berdampak pada produksi 
kelapa sawit.

\section{Implikasi Kebijakan}

Untuk mewujudkan arah kebijakan pembangunan pertanian pada sub sektor perkebunan yang tertuang dalam Rencana Strategis Direktorat Jenderal Perkebunan Tahun 2015-2019, disusun kebijakan yang terdiri dari kebijakan umum dan kebijakan teknis. Kebijakan umum bertujuan untuk mensinergikan seluruh sumberdaya perkebunan dalam rangka peningkatan daya saing usaha perkebunan, nilai tambah, produktivitas dan mutu produk perkebunan melalui partisipasi aktif masyarakat perkebunan, dan penerapan organisasi modern yang berlandaskan kepada ilmu pengetahuan dan teknologi serta didukung dengan tata kelola pemerintahan yang baik. Kebijakan teknis pembangunan perkebunan bertujuan meningkatkan produksi, produktivitas tanaman perkebunan dalam hal ini kelapa sawit yang tefokus pada:

1. Untuk meningkatkan produksi dan produktivitas perkebunan kelapa sawit rakyat pola swadaya di Kabupaten Indragiri Hilir dapat dilakukan dengan cara sebagai berikut:

a. Perluasan areal perkebunan

Perluasan tanaman dilakukan dengan menanam tanaman kelapa sawit pada lahan kosong atau lahan baru dengan menerapkan inovasi teknologi terkini dan disesuaikan dengan kondisi lahan. Pengembangan tanaman kelapa sawit di Kabupaten Indragiri Hilir dilakukan pada tipologi lahan gambut pasang surut, gambut pesisir dan pada lahan pesisir.

b. Penggunaan bibit unggul

Penggunaan bibit unggul kelapa sawit untuk peningkatan produksi dan produktivitas kelapa sawit rakyat pola swadaya sesuai dengan yang direkomendasikan atau yang dianjurkan yaitu jenis Marihat, Topaz, Socfin dan Lonsum.

2. Peningkatan produksi dan produkstivitas kelapa sawit rakyat pola swadaya pada tanaman produktif di Kabupaten Indragiri Hilir dilakukan dengan cara:

a. Meningkatkan pemeliharaan/ perawatan tanaman mulai dari penanaman hinga tanaman menghasilkan dengan lebih mencurahkan tenaga kerja untuk perawatan dengan cara penebasan maupun dengan cara penyemprotan dengan herbisida.

b. Pemberian pupuk mulai dari saat penanaman hingga tanaman menghasilkan sesuai denagn rekomendasi atau anjuran yang berfungsi sebagai tambahan nutrisi yang tidak tersedia oleh alam dan untuk menetralisis tanah.

c. Pembangunan trio tata air sebagai sirkulasi air dan menjaga level air serta menghindari intrusi air laut.

3. Pembangunan infrastruktur perkebunan kelapa sawit dapat mendukung budidaya, pasca panen, dan pemasaran.

\section{KESIMPULAN}

Berdasarkan hasil analisis dan pembahasan sebelumnya maka dapat diambil kesimpulan. Adapun kesimpulan dari penelitian ini adalah

1) Dari aspek produksi dan produkstivitas lahan, usahatani kelapa sawit pada lahan daratan paling tinggi dibandingkan dengan tipologi lahan gambut pasang surut, gambut pesisir dan lahan pesisir.

2) Faktor yang dominan mempengaruhi produksi kelapa sawit di Kabupaten Indragiri Hilir adalah jumlah penggunaan pupuk, tenaga kerja, umur tanaman, herbisida dan dummy tipologi lahan daratan.

3) Implikasi Kebijakan pembangunan perkebunan kelapa sawit di Kabupaten Indragiri Hilir dalam rangka meningkatkan produksi, produkstivitas dan pendapatan usahatani kelapa sawit rakyat dapat melalui pembangunan jalan produksi, penyedian sarana 
produksi dan industri pengolahan kelapa sawit untuk memperpendek jarak dan mempersingkat waktu tranportasi agar TBS dari kebun kelapa sawit ke pabrik. Selanjutnya penggunaan pupuk, tenaga kerja dan tipologi lahan sangat responsif terhadap produksi TBS. Oleh karena itu dalam ushatani kelapa sawit harus mengikuti teknis budidaya yang dianjurkan.

\section{UCAPAN TERIMA KASIH}

Penulis mengucapkan terimakasih kepada Lembaga Penelitian dan Pengabdian Kepada Masyarakat Universitas Islam Riau yang telah mendanai penelitian ini dan kepada bapak dekan fakultas pertanian yang telah memberikan masukan dan saran dalam penulisan artikel ini.

\section{DAFTAR PUSTAKA}

Asrol H and Karya D. 2017. Preparation of Palm Oil Farmers In ISPO Application in Regency Indragiri HilirRiau. Education and Humaniora (ICoSEEH) 08-10 November 2017 Pekanbaru, Indonesia, p.235.

Badan Pusat Statistik. 2016a. Riau Dalam Angka 2015. Pekanbaru: Badan Pusat Statistik Provinsi Riau.

Badan Pusat Statistik. 2016b. Statistik Indonesia. Jakarta: Badan Pusat Statistik Indonesia.

Badan Pusat Statistik. 2017. Statistik Indonesia. Jakarta: Badan Pusat Statistik Indonesia.

Daim C. 2003. Pengembangan Kemitraan dan Dukungan Pendanaannya di Bidang Perkebunan. Bogor: IPB Bogor.

Gatto M, Wollni M, Asnawi R, dan Qaim M. 2017. Oil palm boom, contract farming, and rural economic development: Village-level evidence from Indonesia. World Development 95:127-140.

Gujarati D. 2003. Basic Econometrics, Fourth Edition. New York:
McGraw-Hill Companies,.

Gujarati D. 2008. Basic Econometrics. New York: McGraw-Hill/Irwin, a business unit of The McGraw-Hill Companies, Inc., 1221 Avenue of the Americas.

Gujarati D. 2011. Econometric By Example. New York: McGraw-Hill/Irwin, a Business Unit of The McGraw-Hill Companies.Avenue of the Americas.

Harahap F, Silveira S, dan Khatiwada D. 2017. Land allocation to meet sectoral goals in Indonesia An analysis of policy coherence. Land Use Policy 61:451-465.

Heriyanto. 2017. Analisis Efisiensi Faktor Produksi Karet Di Kabupaten Kampar Provinsi Riau.

Intriligator MD. 1978. Econometric Models, Techniques, \& Applications. New Jersey: Prentice Hall, Englewod Cliffs.

Lifianthi, Oktarina S, dan Aryani D. 2014. Perbandingan kontribusi pendapatan dan pengeluaran konsumsi petani plasma kelapa sawit di dua tipologi lahan di Sumatera Selatan. In Prosiding Seminar Nasional Lahan Suboptimal $2014 \quad$ tema "Pengembangan Teknologi Pertanian yang Inklusif untuk Memajukan Petani Lahan Suboptimal (pp. 139-146). Palembang: Fakultas Pertanian Universitas Sriwijaya.

Mustofa R, Dewi N, dan Yusri J. 2016. Analisis komparasi usahatani kelapa sawit swadaya menurut tipologi lahan Di Kabupaten Indragiri Hilir. Indonesian Journal of Agricultural Economics 7(1):47-55.

Noor M. 2004. Lahan Rawa, Sifat dan Pengelolaan Tanah Bermasalah Sulfat Masam. Jakarta: Raja Grafindo Persada.

Pindyck RS dan Rubinfeld DL. 1998. Econometric Model and Econometric Forecasts (Fourth Edi). New York: McGraw-Hill 
International Editions. Thomas R. 1977. Modern Econometrics an Introduction. Harlow: Addison Wesley Longman.

Verbeek M. 2000. A Guide to Modern
Ecomometrics. Chichester: John Wiley \& Sons Ltd.

Verbeek M. 2017. A guide to modern econometrics (Fifth Edit). Rotterdam: John Wiley \& Sons Ltd. 